\title{
PROTEÇÃO INTEGRAL À CRIANÇA E AO ADOLESCENTE: PROTEÇÃO VERSUS AUTONOMIA?
}

\author{
Esther Maria de Magalhäes Arantes*
}

\section{RESUMo}

Os estudos na área da infância e adolescência vêm se revestindo de extrema complexidade, tanto pela novidade histórica dos direitos de que são titulares - tendo como marco, no plano internacional, a Convenção das Nações Unidas sobre os Direitos da Criança (1989) e, no plano nacional, a Constituição Federal (1988) e o Estatuto da Criança e do Adolescente (1990) -, como pela persistência de dificuldades culturais em aceitar orientaçôes sexuais, religiosas e estilos de vida que se afastam de uma pretensa normalidade médica, psicológica e social. Pensar alguns desafios colocados por esta complexidade é o objetivo deste texto.

Palavras-chave: Proteção integral; criança; adolescente.

\section{Abstract \\ FULL PROTECTION FOR CHILDREN AND ADOLESCENTS: PROTECTION VERSUS AUTONOMY?}

Studies in the field of childhood and adolescence are becoming extremely complex, both because of the historical novelty of the rights they hold - having as landmark in the international arena, the United Nations Convention on the Rights of the Child (1989), and in national level, the Federal Constitution (1988) and the Child and Adolescent Statute (1990) - as the persistence of cultural difficulties in accepting sexual orientation, religion and lifestyles that deviate from a supposed medical, psychological and social normality. Thinking some of the challenges posed by this complexity is the goal of this text.

Keywords: full protection; children; adolescents.

* Doutora em Estudos Humanísticos e do Comportamento (Boston University); Professora do Departamento de Psicologia da Pontifícia Universidade Católica do Rio de Janeiro (PUCRio) e do Programa de Pós-Graduação em Políticas Públicas e Formação Humana da Universidade do Estado do Rio de Janeiro (PPFH-UERJ). 


\section{Apresentando a QUeSTÃo}

Conforme já mencionado em texto anterior, os estudos na área da infância e adolescência vêm se revestindo de extrema complexidade, tanto pela novidade histórica dos direitos de que são titulares - tendo como marco histórico normativo, no plano internacional, a Convenção das Nações Unidas sobre os Direitos da Criança (1989) e, no plano nacional, a Constituição Federal (1988) e o Estatuto da Criança e do Adolescente (1990) -, como pela persistência de dificuldades culturais em aceitar orientações sexuais, religiosas e estilos de vida que se afastam de uma pretensa normalidade médica, psicológica e social (Arantes, 2009).

Tais dificuldades são particularmente sentidas e ganham maior evidência quando se trata de matéria objeto de disputa entre grupos religiosos e minoritários, como, por exemplo, o direito de liberdade de orientação sexual e do uso de preservativos para a prevenção da gravidez e de doenças sexualmente transmissíveis, e do direito ao aborto, nos casos permitidos por lei. Lembramos, aqui, o caso, amplamente divulgado na imprensa nacional, da menina de 9 anos, grávida de gêmeos e que vinha sofrendo abuso sexual por parte do padrasto desde os 6 anos de idade. O caso se tornou público em fevereiro de 2009 e teve grande repercussão, tanto pela pouca idade e estrutura franzina da menina como pela oposição de setores da Igreja Católica à realização do aborto - o que, de fato, veio a acorrer, tendo-se em vista os dois motivos permitidos pela legislação brasileira: gravidez decorrente de estupro e risco de morte da mãe. O próprio Presidente Lula da Silva, declaradamente católico, sentiu-se no dever de vir à público dizer que preservar a vida da menina era o mais importante, afirmando que, neste aspecto, a medicina estava mais correta do que a Igreja. Lembramos que a gravidez da menina, de 1,37 metro de altura e pesando 33 quilos, foi descoberta apenas após ela ter se queixado de dores na barriga e náuseas.

Ainda, a propósito de nossas dificuldades no trato dos direitos de crianças e adolescentes, lembramos a coletânea de textos intitulada Direitos sexuais são direitos humanos, publicada pelo Comitê Nacional de Enfrentamento à Violência Sexual contra Crianças e Adolescentes, em 2008 (Castanha, 2008). Em que pese a importância e a oportunidade de sua publicação, há que se notar, no entanto, na maioria de seus textos, certa tendência a substituir a discussão dos direitos sexuais e reprodutivos pela denúncia do abuso sexual intrafamiliar e da exploração sexual comercial de crianças e adolescentes. Embora a garantia dos direitos de crianças e adolescentes pressuponha o monitoramento, a prevenção e o combate às suas violações, não há que confundi-los. Não se trata, evidentemente, de negar a gravidade do problema do abuso e da exploração sexual, mas 
apenas de assinalar a necessidade da discussão sobre os direitos e não apenas sobre suas violaçôes. Sem uma clareza maior do que os direitos significam e quais as implicações daí decorrentes, no caso de crianças e adolescentes, o próprio combate às violações fica prejudicado.

Neste sentido, em um dos textos da coletânea, Matta e Correia (2008) chamam a atenção para o seguinte fato: algumas das denúncias de violência sexual levadas à $12^{\text {a }}$ Promotoria Criminal de Fortaleza foram feitas, na realidade, por pais ou responsáveis que não concordavam com a orientação sexual dos filhos ou com a idade ou estado civil dos parceiros. Surras, cárcere privado, exposição da intimidade, dentre outros, foram relatados pelos filhos adolescentes, demandando estes o direito de viverem opçôes sexuais e escolha de parceiros sem cerceamentos.

Analisando esses casos, propõem as autoras que o bem jurídico a ser tutelado não deve ser a moralidade pública e os bons costumes e sim os direitos sexuais e reprodutivos dos adolescentes, fazendo-se necessário identificar, dentre os casos notificados como violência sexual, aqueles cuja intenção é apenas o controle do adolescente e não a proteção de seus direitos. Alertam-nos para o fato de que a temática da sexualidade na adolescência tem sido predominantemente tratada enquanto problema e quase nunca como uma conquista.

Os direitos sexuais e reprodutivos devem ser o foco ao se tratar do adolescente, sobrepondo-se, como bem jurídico, à moralidade pública ou interesses familiares. Faz-se necessário sensibilizar os operadores do direito para identificar, nos casos notificados, aqueles cuja intenção implícita é a repressão do adolescente. Os princípios constitucionais da liberdade e dignidade humana devem ser priorizados na interpretação das normas jurídicas penais levando em conta o melhor interesse da criança e do adolescente. Os direitos sexuais devem ser interpretados numa perspectiva de afirmação positiva da sexualidade de crianças e adolescentes em todos os seus aspectos, com a aplicação do Direito Penal numa perspectiva de tutela da dignidade sexual da pessoa, levando em conta o contexto social (Matta \& Correia, 2008: 71).

Concordamos inteiramente com as autoras, chamando a atenção apenas para os desafios colocados pela complexidade do tema, uma vez que o reconhecimento da capacidade de crianças e adolescentes para o exercício dos direitos afetivosexuais e reprodutivos, bem como de outros direitos, não é uma capacidade absoluta, não abolindo diferenças entre crianças, adolescentes e adultos. Por certo que as autoras não desconhecem estes desafios, que compreendem, inclusive, pensar 
"como proceder quando a violação deste direito se reveste da aparência do dever de proteção [...]” (Matta \& Correia, 2008: 76). Neste sentido, pensar os direitos humanos de crianças e adolescentes requer o reconhecimento de uma tensão, mas não necessariamente de uma contradição, entre pessoa em desenvolvimento e sujeito de direitos, entre proteção e autonomia.

É também o que pensa Nogueira Neto (2008), para quem as limitações colocadas pela lei devem ser entendidas de acordo com a perspectiva emancipatória dos Direitos Humanos e não de forma castradora, já que a sexualidade deve ser reconhecida e garantida como um dos direitos fundamentais indisponíveis da pessoa humana, incluindo crianças e adolescentes.

Assim, delineia-se uma questão fundamental, a de como entender o sentido da Proteção Integral a que têm direito crianças e adolescentes, sem confundi-la com a proteção dispensada pelo sistema tutelar menorista, vigente no Brasil em quase todo o século XX.

O que se destaca neste debate é o fato de não mais se restringir ao mero reconhecimento do direito à proteção e ao acesso não discriminatório de crianças e adolescentes aos serviços e bens culturais, reivindicaçōes que se tornaram o apanágio dos movimentos sociais. O grande desafio do momento atual é equacionar a tensão que se instala entre conceder maior autonomia à infância e à adolescência, direito de voz e de participação política, com vistas ao alcance daquilo que definimos como meta para atingirmos a excelência humana, portanto a felicidade, e o risco de que esta prática possa favorecer uma certa omissão dos adultos e das instituiçôes em construir junto com as crianças e os adolescentes metas que garantam a proteção dos direitos das crianças e dos adolescentes em um contexto de definiçóes claras em relação ao bem humano e à felicidade humana. Se, por um lado, estamos convencidos de que os princípios tradicionais de proteção e direitos da criança e do adolescente precisam ser revistos, por outro, é igualmente verdadeiro que eles não podem ser de modo algum descartados, mas sim retomados dentro de um novo contexto (Souza, 2008: 12-13).

\section{O DIREITO DA CRIANÇA DE SE EXPRESSAR E DE SER OUVIDA}

Mas os desafios em relação ao exercício dos direitos de crianças e adolescentes não se limitam ao terreno dos direitos sexuais e reprodutivos. Outro direito que vem sendo objeto de intenso debate é o direito da criança de expressar suas 
opiniōes livremente. Neste sentido, lembramos a disputa pela guarda do menino de 9 anos, filho de mãe brasileira e pai americano, caso que ganhou ampla divulgação na mídia após a morte de sua mãe e que por diversas vezes teria manifestado o desejo de permanecer com o padrasto no Brasil e não de residir com o pai biológico nos EUA - uma vez que este requereu, na Justiça Federal brasileira, que o menino retorne aos Estados Unidos, de acordo com a Convenção de Haia (Convenção sobre os Aspectos Civis do Sequestro Internacional de Crianças, de 1980).

Assinalando a complexidade do caso, Paulo Vanucchi, ministro da Secretaria Especial de Direitos Humanos da Presidência da República, ponderou que a Justiça Federal não deve decidir sobre a guarda do menino levando em conta apenas as declaraçôes da própria criança. Considera que um eventual peso dado às suas manifestaçôes hoje poderá causar-lhe danos e arrependimento futuros, já que a criança é ainda muito jovem. "A criança não deve ser forçada a decidir. Isso irá trazer dramas psíquicos no seu futuro. Chamá-la para decidir é certeza de problemas lá na frente. A proteção a ele tem que ser integral" (O Globo, 23/04/2009: 12).

Neste caso específico e segundo o advogado da família brasileira, a opinião do menino deve sim, ser levada em consideração na decisão judicial, tendo em vista o art. 12 da Convenção sobre os Direitos da Criança - também referida como Convenção Internacional dos Direitos da Criança ou Convenção das Nações Unidas sobre os Direitos da Criança. Vejamos o art. 12:

1. Os Estados Partes assegurarão à criança que estiver capacitada a formular seus próprios juízos o direito de expressar suas opiniōes livremente sobre todos os assuntos relacionados com a criança, levando-se devidamente em consideração essas opiniões, em função da idade e maturidade da criança.

2. Com tal propósito, se proporcionará à criança, em particular, a oportunidade de ser ouvida em todo processo judicial ou administrativo que afete a mesma, quer diretamente quer por intermédio de um representante ou órgão apropriado, em conformidade com as regras processuais da legislação nacional.

Por se tratar de matéria envolvendo relaçôes internacionais, a Advocacia Geral da União (AGU) tem defendido o cumprimento da Convenção de Haia. Graças a esta Convenção, várias crianças já retornaram às suas famílias no Brasil, existindo, igualmente, diversos processos de pais pedindo repatriação de crianças trazidas para o Brasil. De acordo com o art. $1^{\circ}$, são objetivos da Convenção de Haia (1980):

a) assegurar o retorno imediato de crianças ilicitamente transferidas para qualquer Estado Contratante ou nele retidas indevidamente; 
b) fazer respeitar de maneira efetiva nos outros Estados Contratantes os direitos de guarda e de visita existentes num Estado Contratante.

No entanto, dado que o caso envolve não apenas a paternidade biológica mas também a paternidade socioafetiva e a proteção psicológica e emocional da criança (Cristo, 2009), há quem veja certo antagonismo, conflito ou disputa de interesses entre a Convenção de Haia e a Convenção sobre os Direitos da Criança, além de conflitos com o Estatuto da Criança e do Adolescente.

Em texto intitulado "A criança chega ao Supremo Tribunal Federal", Darlan (2009), após lembrar que tanto a Convenção sobre os Direitos da Criança como o Estatuto da Criança e do Adolescente reconhecem o direito da criança de expressar suas opiniōes livremente, faz uma comparação entre a Convenção de Haia e a Doutrina da Situação Irregular do Menor, por um lado, e a Convenção sobre os Direitos da Criança e a Doutrina da Proteção Integral, por outro.

Outro aspecto [...] é quanto à prevalência da doutrina da situação irregular sepultada em nosso país com a vigência do Estatuto da Criança e do Adolescente, mas que ainda encontra vários adeptos no cenário jurídico, sobretudo nos mais conservadores, e a doutrina consagrada no texto constitucional da proteção integral que erigiu crianças e adolescentes à condição de sujeitos de direitos. Os primeiros acreditam que a criança em questão estaria em situação irregular no país por haver sido sequestrada por sua mãe [...], enquanto que os outros que defendem o respeito à doutrina vigente da proteção integral colocam a criança na condição de protagonista de sua cidadania e lhe outorgam o direito de ser ouvida e ao manifestar seu desejo de que prevaleçam suas relações afetivas e culturais ver respeitada sua manifestação de vontade (Darlan, 2009: 1).

Outro caso, envolvendo relações internacionais, é o de dois irmãos, uma menina de 4 anos e um menino de 12, filhos de mãe brasileira e pai austríaco, tendo a menina falecido no Brasil em junho de 2009, em circunstâncias ainda não totalmente esclarecidas, havendo indícios de maus-tratos causados pela tia com quem as crianças residiam no Brasil.

Em matéria de Uchôa (2009), publicada no portal Globo.com, o pai disse que mesmo tendo a guarda compartilhada das crianças sua ex-mulher embarcou com os dois filhos para o Brasil, em janeiro de 2008. Após este fato, ganhou na justiça austríaca a guarda integral dos filhos. Segundo a família da mãe, esta encontra-se desaparecida há alguns meses e sofre de problemas mentais. Diz o pai que gastou soma considerável de dinheiro com detetives e advogados para conseguir reaver os dois filhos. "Paguei e pagaria de novo para ter a minha filha de 
volta. Tenho pavor da Justiça brasileira. Foi petição atrás de petição e nada foi feito. Para que o Brasil assinou a Convenção de Haia se não a cumpre? As crianças já deveriam ter voltado para a Áustria, reclama” (Uchôa, 2009: s/p).

Segundo a família da mãe, o contato com o pai foi dificultado porque a mãe das crianças teria dito que o ex-marido havia abusado sexualmente do filho. " $\mathrm{Na}$ Áustria nunca havia tido essa história. Aqui eu virei abusador?", indaga [...]. O menino inocentou o pai na última sexta-feira (21), em depoimento à Justiça na 27a Vara Federal do Rio" (Uchôa, 2009: s/p).

Se neste caso específico o depoimento do menino de 12 anos mostrou-se oportuno e relevante para inocentar o pai da suspeita de abuso sexual, em outros casos o depoimento apresenta-se contraindicado, seja pelas circunstâncias do caso, pela pouca idade ou pela situação de sofrimento vivenciada pela criança ou, ainda, por qualquer outro motivo onde o superior interesse da criança e do adolescente esteja em jogo. Lembramos, aqui, o caso da menina Isabella, de 5 anos, morta em 2008, supostamente por ação do pai e da madrasta, na presença de dois irmãos pequenos, tendo sido ventilada a hipótese de a criança mais velha, de 3 anos, ser chamada como testemunha (Arantes [2008] 2009).

O próprio Conselho Nacional dos Direitos da Criança e do Adolescente (CONANDA), principal órgão, no Brasil, do Sistema de Garantias dos Direitos da Criança e do Adolescente (SGDCA), em Nota Pública datada de 8 de maio de 2008, manifestou-se contrário à inquirição da criança como testemunha no caso citado, pelas seguintes razóes:

1) O denominado "depoimento sem dano" ainda não foi implementado no Estado de São Paulo. No Estado do Rio Grande do Sul, onde foi implementado, são ouvidas "vítimas" e não "testemunhas";

2) O artigo 206 do Código de Processo Penal prevê que pais, mães, filhos e cônjuges podem se eximir da obrigação de depor. Nesse caso, a criança de 3 anos não tem como manifestar sua vontade real e inequívoca de depor ou não depor;

3) $\mathrm{O}$ artigo 208 do Código de Processo Penal também prevê que a testemunha de menos de 14 anos não presta compromisso, portanto também não é obrigada a depor. Dessa forma, o depoimento, mesmo que ocorresse, teria um valor relativo;

4) O artigo 18 do Estatuto da Criança e do Adolescente (Lei 8.069/1990) dispōe que "é dever de todos velar pela dignidade da criança e do adolescente, pondo-os a salvo de qualquer tratamento desumano, violento, aterrorizante, vexatório ou constrangedor". Certamente, a inquirição de qualquer criança acarretaria consequências para seu desenvolvimento psíquico, independentemente 
da forma utilizada. Em um caso complexo e de tanta repercussão, onde todas as informaçōes são exaustivamente tornadas públicas imediatamente, certamente geraria grande constrangimento para uma criança de três anos. Eis que além de ter sua imagem e privacidade extremamente devassadas, acentuaria as dificuldades de convivência familiar e comunitária. Além disso, avaliamos as dimensões e repercussões emocionais ao longo do desenvolvimento desta criança ao se culpar e/ou ser culpada pela possível prisão dos pais. Isso não significa que o crime e a superação dos traumas não devam ser trabalhados nas terapias. O que não podemos aceitar é a exposição desta criança perante a Justiça e, consequentemente, perante toda a sociedade brasileira.

5) Considerar a proteção do mundo subjetivo da criança também é pensar na garantia dos direitos humanos de uma pessoa em situação peculiar de desenvolvimento, que tem direito de calar e elaborar seus conflitos. Outra reflexão é o risco da exposição do universo psicológico de uma criança e com isso romperem-se as fronteiras da proteção em momentos de extrema fragilidade psicológica.

6) A questão que se coloca nesta problematização é a de que inquirir qualquer criança é algo polêmico e muito delicado. No caso específico, nos parece que a criança, aos três anos de idade, se encontra no período de estruturação psíquica e vivenciando repetidos acontecimentos traumáticos. Portanto, não vislumbramos qualquer benefício ao processo e principalmente à criança, que já se encontra extremamente vulnerável, a citada inquirição como testemunha.

7) Nesse sentido, respeitando as competências e atribuições, além da imparcialidade e discricionariedade do Ministério Público e do Poder Judiciário, apresentamos o presente posicionamento e recomendação.

Fundamentando-se, justamente, no direito da criança de se expressar e de ser ouvida, encontra-se no Congresso Nacional, aguardando votação, o Substitutivo ao Projeto de lei da Câmara no 4.126 de 2004 (tramitando no Senado Federal como PLC no 35 de 2004), que trata da inquirição judicial de crianças. Se aprovado o Substitutivo, significará o acréscimo de toda uma Seção VIII ao Título VI, do Capítulo III do Estatuto da Criança e do Adolescente, alterando também o Código de Processo Penal. Trata-se, portanto, de Substitutivo que dispóe sobre a forma de inquirição de testemunhas e produção antecipada de prova nas situações que envolverem crianças e/ou adolescentes vítimas e testemunhas de crimes (Arantes, 2008).

Busca-se, com esta proposta, regulamentar a inquirição judicial de crianças vítimas ou testemunhas de crimes, estabelecendo técnicas consideradas menos danosas à tomada de seus depoimentos. Em nome destes mesmos direitos huma- 
nos, no entanto, inúmeros questionamentos são feitos ao Projeto de Lei, não havendo, ainda, consenso que permita a votação do Projeto no Congresso Nacional.

Em simpósio internacional sobre tomada de depoimento especial de crianças e adolescentes, realizado em Brasília nos dias 26 a 28 de agosto de 2009, em que procedimentos utilizados em outros países foram apresentados aos convidados presentes, tivemos a oportunidade de constatar que não se pode, sem maiores considerações, transportar procedimentos próprios de um país para outro. Fomos informados, por exemplo, por pesquisadores norte-americanos que, em seus estados, as crianças são obrigadas a testemunhar e a fazer juramento de que dirão somente a verdade, bem como comparecer ao julgamento, salvo em alguns casos específicos. Nos depoimentos juramentados as crianças podem ser punidas caso não digam a verdade. Assim, para que se apresentem para depor, as crianças são previamente preparadas, seja para que possam fazer o juramento, seja para que a memória esteja focada apenas no objeto do depoimento, seja ainda para diminuir ou controlar os sintomas da criança como medo, pavor, ansiedade, insegurança etc. Ademais, nos informaram que, em geral, as vítimas não se sentem satisfeitas a não ser que os autores dos crimes sexuais sejam punidos severamente e que o júri tende a dar mais crédito à denúncia do abuso caso a criança testemunhe, uma vez que o sistema norte-americano exige confronto presencial, face a face, entre vítima e acusado. Também nos foi dito que, em alguns estados, o crime sexual contra crianças pode ser punido com a pena de morte, levando-nos a indagar se já houve casos em que crianças, depondo contra seus pais, os condenaram à pena de morte. Além do mais, alguns dos procedimentos utilizados em pesquisas com crianças, com o objetivo de testar a fidedignidade da memória, nos pareceram altamente invasivos. Para Azambuja,

A ordem constitucional brasileira, garantidora do princípio da dignidade humana e da doutrina da Proteção Integral à Criança, estatuída em 1988, passa a exigir a revisão de muitas práticas consolidadas ao longo do tempo, embasadas no não reconhecimento de direitos à população infanto-juvenil. O Melhor Interesse da Criança rechaça a velha prática de inquirir a vítima de violência sexual intrafamiliar, em face das consequências nefastas que acarreta ao desenvolvimento físico, social e psíquico da criança, considerada, pela lei, pessoa em fase especial de desenvolvimento (Azambuja, 2009: 27-28).

Para a autora,

Expressar as próprias opinióes, como menciona o documento internacional (Convenção das Nações Unidas sobre os Direitos da Criança), tem sentido 
diverso de exigir da criança, em face de sua peculiar condição de pessoa em desenvolvimento, em Juízo ou fora dele, o relato de situações extremamente traumáticas e devassadoras ao seu aparelho psíquico (Azambuja, 2006: 434).

Segundo Azambuja, "não há que confundir a hipótese inovadora do art. 28, parágrafo $1^{\circ}$, do ECA, com a oitiva coagente da criança. Nestes casos a oitiva visa essencialmente produção da prova da autoria e materialidade [...] recaindo na criança uma responsabilidade para a qual não se encontra preparada” (Azambuja, 2006: 435).

No entanto, segundo os partidários da metodologia denominada Depoimento Sem Dano, depor em juízo é um direito da criança, sendo que tal metodologia, considerada amigável à criança, pode diminuir o número de vezes em que seu depoimento é requerido, reduzindo, assim, possíveis danos causados pela intervenção judicial. Além do mais, a técnica melhoraria as condições da prova, possibilitando a condenação dos autores do abuso, uma vez que, em muitos casos, a vítima é a única testemunha.

\section{EnTRE O CUIDADO E O ABUSO}

Outro caso, envolvendo mãe brasileira e pai de outra nacionalidade, ocorreu no início de setembro de 2009, em Fortaleza, e também ganhou destaque no noticiário nacional. Segundo os relatos, dois turistas, de 70 e 75 anos, funcionários públicos federais de Brasília, chamaram a polícia porque ficaram incomodados com o modo como um homem acariciava e beijava uma menina de 8 anos de idade. A polícia compareceu ao local e prendeu o italiano, de acordo com o artigo 217-a da Lei 12.015, que versa sobre o crime de estupro, aprovada em agosto de 2009. Se condenado, o italiano pode cumprir pena de 8 a 15 anos de reclusão. A delegada ouviu a criança, com apoio de assistentes sociais e de psicólogos, tendo a criança relatado que apenas brincava com o pai. Como a barraca de praia em que o italiano estava com a família é monitorada por câmeras, acredita-se que as fitas com as gravações possam trazer algum esclarecimento sobre o caso. A mãe alegou que demonstrações de carinho (selinho) são comuns entre os italianos e que, para ela, o pai foi mal interpretado:

Minha opinião é que eles confundiram, interpretaram mal. Em meio a tantos casos de abuso sexual que já aconteceram, eles (as testemunhas) viram um homem, estrangeiro, branco, com uma menina muito mais escura. Não tentaram se informar e nem saber quem era. Imaginaram logo que era um estrangeiro 
que estava tentando ficar com uma menina de 8 anos. A denúncia foi motivada por um pouco de preconceito. Eles não sabiam que ele era o pai dela (O Globo, 06/09/2009: 12).

Dos 942 comentários deixados no Painel do Internauta do Globo.com (Debate Jornal Hoje, acessado em 03 e 04/09/2009), um grande número indica preocupação com as consequências que podem advir de prejulgamentos, com a maneira como as leis estão sendo votadas e executadas no Brasil e também com o avanço do controle sobre a privacidade e intimidade dos cidadãos. Ao lado de mensagens que desejam que a lei seja respeitada na apuração dos fatos, há também os comentários que desqualificam os turistas estrangeiros, em geral, por serem "pedófilos"; as autoridades brasileiras, por serem "corruptas" e as testemunhas, por serem "idosos preconceituosos". De qualquer modo, o número de quase mil comentários indica o quanto o assunto vem mobilizando e preocupando a sociedade brasileira, colocando a questão da tênue linha que separa o que é visto do que é entendido, o que é o cuidado e o que é o abuso, o que é a omissão e o que é o denuncismo.

Vejamos alguns desses comentários - que aqui foram reproduzidos com pequenas correções de redação:

- Uma notícia dessa nem devia estar na imprensa, pois se for um equívoco vai ficar marcado para sempre.

- Se for denúncia descabida, fruto de uma perversão dos que denunciaram, desejo que o casal que chamou a polícia seja processado por danos morais e porque terá causado abuso psicológico também à criança.

- É um absurdo o que estão fazendo com esse italiano! É mais do que natural pais beijarem seus filhos. Enquanto isso autoridades, pedófilos declarados, estão à solta por aí! Quanta hipocrisia! Daqui a pouco estarão proibindo as praias de nudismo por atentado violento ao pudor. Que coisa!

- Não sei onde vai parar esse mundo com essa inacreditável onda de PURITANISMO! Nós - o povo BRASILEIRO - somos assim? Ficamos assim? Por que ficamos assim??

- Quer dizer que na Itália é normal atos libidinosos com criança? É pedofilia somente no Brasil? Essa brasileira, esposa do italiano, também deve ser punida por conivência.

- A questão é que nos últimos meses temos sidos bombardeados com revelações que beiram a barbárie envolvendo pais e filhos [...]. Aí, tudo que vemos passa a ser suspeito. 
- Mais libidinoso que o ato é a forma desrespeitosa como estão sendo tratadas essas pessoas que denunciaram o caso à polícia - velhos, desocupados, etc. Precisamos acima de mais nada apurar os fatos e, aí sim, manifestar opiniōes, mas com respeito, ou será que todos que estão julgando nunca erraram?

- No caso de um pai que tem que dar banho na filha na praia será crime, imagine se fosse uma enteada.

- Não custa investigar. O problema é a prisão. Não vejo nada demais em um pai ou uma mãe beijar o filho ou a filha na boca (um selinho). É apenas, em princípio, uma demonstração de carinho. Isso na Itália, no Brasil e em qualquer parte do mundo. Imaginem se o pai for inocente. $\mathrm{O}$ constrangimento.

- Essa é uma acusação grave demais, que pode transformar a vida de uma pessoa num inferno e também afetar a criança, que antes poderia estar muito bem. Se eu fosse o italiano, processava os idosos.

- Quando a lei é mal interpretada dá nisso.

- O grande problema é que os analfabetos funcionais chegaram ao poder e não têm capacidade para redigir as leis. VIVA O PAÍS DOS ANALFABETOS !!!!!!!! - A partir do momento em que o simples testemunho de pessoas, que em nada têm a ver com os envolvidos, estiver provocando injustiças, será melhor que haja câmeras filmando nossas vidas 24 horas para que possam então ser evitadas as injustiças. Se comprovado ótimo, se não, puna-se os idosos.

- Vocês estão esquecendo que não foram só beijos. Pelo que as testemunhas disseram o pai acariciou a filha nas partes íntimas. Então, se for comprovada, tem sim que ser preso e virar mulherzinha na cadeia. Se for preso aqui os detentos vão adorar um de fora.

Independentemente dos desdobramentos que terá este caso, conflitos envolvendo pessoas de outras nacionalidades e culturas - e mesmo internamente, em relação às populações indígenas e demais grupos étnicos residentes no Brasil devem nos levar a pensar sobre os diferentes modos de nossa presença no mundo e as cautelas necessárias quando se pensa em intervir junto a esses grupos. Constantemente somos informados de intervenções bem intencionadas mas desastrosas porque não levaram em consideração as especificidades do caso ou do contexto socioeconômico-cultural. Não é incomum, por exemplo, crianças brasileiras voltarem para desmentir o depoimento de que haviam sido abusadas sexualmente, após sofrerem as consequências que se seguiram ao depoimento. Também não é incomum que adolescentes sejam mortos por determinação da rede criminosa à qual pertenciam ou estavam ligados, após cumprirem a medida socioeducativa de 
privação de liberdade e desejarem "mudar de vida"; ou em decorrência de acertos de conta ou retaliações de pessoas ou grupos que apenas aguardavam a saída do adolescente da unidade de internação.

Ou seja, no primeiro caso, o depoimento da criança pode ter sido eficaz para condenar o autor do abuso mas não para melhorar sua vida e, no segundo caso, a medida socioeducativa foi eficaz para fazer nascer no adolescente o desejo de uma outra vida, mas não para construir as condiçōes em que isto seria possível. Daí a importância de que as açôes e propostas para as crianças e os adolescentes, vítimas ou autores de atos infracionais, não se reduzam a ações isoladas, mas caminhem na perspectiva do fortalecimento do Sistema de Garantia de Direitos da Criança e do Adolescente e das Redes de Atendimento, bem como do fortalecimento de políticas sociais básicas inclusivas e de qualidade. Sem que o SGDCA funcione adequadamente, as medidas de Proteção Especial e Socioeducativas podem, inclusive, ter o efeito oposto ao que se deseja, agravando a situação da criança e do adolescente que, em muitos casos, já correm risco de morte.

Traficantes assassinaram ontem Raissa Cristina de Moraes, de 5 anos, na escadaria do Beco da Tranquilidade, em Madureira. O motivo? A menina viu quando os bandidos executaram o pai dela, [...] de 38 anos. Segundo moradores, o homem foi morto devido a uma dívida com a facção criminosa que domina a área (O Globo, edição de 09/02/2009: 12).

Trouxemos estes casos, amplamente divulgados na imprensa escrita e televisiva, e também na internet, para exemplificar o quanto é complexa e polêmica a questão de se convocar crianças e adolescentes para deporem em processos judiciais, algumas delas correndo risco de morte pelo fato de terem presenciado crimes, como no caso acima. Neste sentido, Carlos Nicodemos (2008), Coordenador Executivo da Organização de Direitos Humanos - Projeto Legal, responsável pela execução do Programa de Proteção às Crianças e Adolescentes Ameaçados de Morte (PPCAAM), pondera que, havendo risco de morte, crianças e adolescentes não devem testemunhar, prevalecendo o princípio do superior interesse da criança.

A atuação da Organização de Direitos Humanos - Projeto Legal norteou-se pela necessidade de desvinculação teórica e prática do programa em relação à experiência do PROVITA - Programa de Proteção a Vítimas e Testemunhas -, cuja lógica da proteção está pautada na contrapartida da vítima na colaboração com o Estado na investigação de crimes. [...]

Com isso procurava-se afastar o "uso" de crianças e adolescentes na condição de testemunhas para processos criminais, além de apontar ao norte do SGD - 
Sistema de Garantia de Direitos (Resolução no 113 do CONANDA - Conselho Nacional dos Direitos da Criança e do Adolescente) - para a formulação de uma política de atenção especial para as crianças e adolescentes ameaçados de morte (Nicodemos, 2008: 7).

Estas ponderações nos parecem bastante relevantes, devendo ser levadas em consideração nos debates sobre o Substitutivo ao Projeto de Lei no 4.126 de 2004, já mencionado.

Manifestando preocupação neste sentido, em 26 de agosto de 2009, o Fórum Nacional de Defesa da Criança e do Adolescente (FNDCA) lançou um Manifesto em Defesa dos Direitos Humanos Infanto-juvenis. Dada a extrema importância deste pronunciamento para o tema aqui em discussão, o reproduzimos abaixo, na íntegra:

O Fórum Nacional DCA, espaço democrático da sociedade civil dedicado à articulação e mobilização da sociedade e luta pela efetiva implementação do Estatuto da Criança e do Adolescente e a efetivação do controle social, se articula com 27 Fóruns Estaduais e mais de 50 entidades filiadas que atuam em nível nacional, envolvendo quase mil entidades, entre organizações de atendimento, de defesa, conselhos de classe, sindicatos, sendo hoje a maior coalizão do Brasil na área da criança e do adolescente. Somos plurais. Nem sempre conseguimos os consensos em todas as discussões. Isto porque o fórum é democrático por natureza e origem e reflete diferentes pensamentos.

Desde a sua origem, o Fórum Nacional estabeleceu como estratégia política e operacional de articulação os chamados "eixos comuns de trabalho", definidos como: monitoramento das políticas públicas, fortalecimento do CONANDA e garantia das conquistas do ECA e da Constituição Federal. Assim, no processo histórico de luta no país pelos direitos de crianças e adolescentes o Fórum Nacional DCA vem sendo sujeito significativo na incidência política, na medida em que reúne entidades que, em que pese seus diferentes matizes conceitualjurídico e técnico-operativo, situam-se num campo de referência ética comum que é o da promoção e defesa de direitos humanos de crianças e adolescentes. Ainda que prática antiga, ganhou lugar no debate público, nos últimos anos, uma possível necessidade de implantação de mecanismos judiciais para escuta de criança/adolescente envolvidas em situação de violência sexual, o que fez colocar na agenda brasileira posiçóes opostas instalando uma polêmica de seu significado como metodologia a ser implantada no sistema de justiça brasileiro. É nesta direção que se parte de um consenso no Fórum da importância de aprofundar essa reflexão problematizando-a e elegendo como foco a criança, 
entendendo que devem ser discutidos os mecanismos de promoção e proteção dos direitos em primeiro plano.

Perguntamos se ao se elevar como objeto de preocupação a responsabilização do abusador não se corre o risco de um deslocamento da discussão, uma vez que ao remeter a ideia de resolutividade ao sistema de justiça perde-se de horizonte o maior interesse pela proteção da criança/adolescente, em nome da produção de prova. Priorizar os trâmites judiciais como melhor resposta para enfrentar a problemática que envolve a violência praticada contra crianças/ adolescentes significa não apenas encontrar uma solução parcial, mas, inclusive, equivocada de enfrentamento. Portanto, chamamos atenção para a necessidade da ampliação do debate com foco na definição de fluxo de atendimento, não restringindo o debate ao procedimento judicial de responsabilização.

À luz da proteção integral o direito de ser ouvida é diametralmente oposto de uma exigência de depoimento, de uma pessoa em condição peculiar de desenvolvimento exigente de total respeito e cuidado na preservação da dignidade que detém a criança/adolescente. Na realidade a prática da oitiva que tem feito parte do sistema de justiça brasileiro já há muito não se apresenta como um mecanismo que coaduna com a doutrina da proteção integral e todos os princípios a ela referidos, sendo inúmeros os exemplos em que se podendo levar em consideração outros instrumentos auxiliares para apreender os fatos em sua amplitude, como o estudo social e a perícia, busca-se encontrar a prova por meio da oitiva, boa parte das vezes sem levar a efeito a égide da proteção e da prioridade absoluta.

É fato que a rede de proteção está fragilizada na sua estruturação, articulação e integração das instâncias públicas governamentais e da sociedade civil, portanto deve ser analisada na sua totalidade, e no que diz respeito a ela toda é sempre preciso pensar nas implicações, seja de serviços, seja do ponto de vista procedimental, para a criança, para a família e, neste caso, também para o próprio abusador. Por outro lado, deve-se pensar a escuta em todos os espaços da rede e de modo geral em todas as políticas sociais públicas, assim como todos os profissionais, garantidas as atribuiçôes específicas, devem estar preparados para lidar com crianças e adolescentes qualquer que seja o espaço que ocupe na rede de atendimento, no sistema de justiça e proteção legal ou no controle das ações de promoção e defesa de direitos.

Por isso entendemos que o debate não pode ser reducionista, pois não se deve encontrar alternativas tópicas em razão das inconsistências ou incoerências hoje verificadas no Sistema de Garantia de Direitos (SGD). Do mesmo modo, o problema da violência não se resolve com instalação operacional para garantir 
eficácia ao aprisionamento. Em nome da eficácia da instrução processual não se pode gerar outros e novos danos, uma vez que em vez de ser vista propriamente como sujeito de direitos em peculiar estágio de desenvolvimento, crianças/adolescentes passam a ser fontes de informação, de forma que todo o processo penal acaba voltado mais para a penalização do acusado do que para a vítima, não reparando - ou minimizando - os danos sofridos pela mesma.

O Fórum DCA, como espaço de controle social, vem cotidianamente realizando um sistemático investimento em nome da efetivação da política voltada para os direitos da criança/adolescente, seja pela defesa de implementação da Política, dos Planos e Programas para este segmento, seja pelas manifestaçôes públicas em defesa do interesse maior da criança/adolescente, a exemplo das posições assumidas contra a redução da maioridade penal, o trabalho infantil, as violências sexuais.

O ECA é instrumento político-normativo que ainda precisa de base concreta para efetuar uma política pública que garanta a proteção integral e faça tornar realidade o Sistema de Garantia de Direitos por ele preconizado. É, sobretudo, instrumento de direitos humanos; mas não se pode negar que iniciativas bem intencionadas nos revelam, senão por oposição ao menos pela contradição, as tensões entre as práticas político-jurídicas, sociais, culturais e econômicas e, em vez de buscar garantir a proteção ante as variadas formas geradoras e/ou mantenedoras da desigualdade social, opressão e violência, podem reafirmá-las.

Finalmente, compreendemos que a sociedade civil deve participar deste debate, de modo efetivo, o que não elimina as tensōes, mas garante uma abertura na sua percepção na medida em que deve envolver os vários segmentos e as várias instâncias do SGD em todas as dimensōes e eixos estratégicos de Promoção, Defesa e Controle da Efetivação. É dessa forma que os direitos da criança/ adolescente inscritos na moderna agenda dos direitos humanos no país podem ganhar lugar efetivo na realidade.

\section{ConClusốes}

Segundo a socióloga Irène Théry ([1992] 2007), por ocasião da adesão à Convenção das Nações Unidas sobre os Direitos da Criança, intenso debate se passou na França entre os que enfatizavam os novos direitos das crianças e os que enfatizavam o aspecto da proteção.

Para Théry ([1992] 2007), a expressão "direitos da criança" tem dois sentidos históricos distintos, vinculados a diferentes tradições. Na tradição filosófica 
que enfatiza a proteção, o homem só se torna verdadeiramente livre ao completar o processo educativo que o faz aceder à autonomia e à responsabilidade. Neste sentido, a menoridade significa que, embora titular de direitos, a criança não pode ser intimada a exercê-lo imediatamente por si mesma. Mas haveria, ainda, uma segunda tradição, favorável à autodeterminação das crianças e que, segundo a autora, teria encontrado, hoje, uma renovação, através da luta contra a discriminação jurídica e mediante a reivindicação de novos direitos para as crianças. Dentre essas duas tradições dos direitos das crianças, qual a que funda a Convenção sobre os Direitos da Criança, de 1989? - indaga Théry.

Segundo a autora, a Convenção de 1989 não afirma nenhuma das duas tradiçôes inteiramente, já que ao lado dos direitos de proteção, que pressupõem a menoridade jurídica, acrescenta novos direitos, que pressupóem a capacidade jurídica. Para a autora, o fato de que estejam presentes na Convenção estas duas lógicas, que considera antagônicas, constituiu uma verdadeira contradição, para a qual a Convenção não aponta nenhuma solução.

Em primeiro lugar, é preciso enfatizá-lo, a Convenção entende "criança” estritamente no sentido de "menor" e não põe absolutamente em questão o conceito de "menoridade jurídica". Em certo sentido, portanto, emprega "direitos da criança" na mesma linha da Convenção de Genebra de 1924 e da Declaração da ONU de 1959: seu preâmbulo e numerosos artigos definem claramente os direitos da criança como direitos a "uma proteção especial", e esses direitos são reafirmados com muita força. Contudo, por outro lado, somam-se a esses direitos à proteção outros tipos de direitos, os quais só têm sentido caso exercidos pelos seus beneficiários: direitos à liberdade de opinião (art. 12), à liberdade de expressão (art. 13), à liberdade de pensamento, de consciência e de religião (art. 140), à liberdade de associação (art. 150); em suma, direitos que pressupõem a capacidade jurídica, quer dizer, a responsabilidade (Théry, [1992] 2007: 139-140).

Resguardadas as diferenças entre Brasil e França, este não é o nosso entendimento, uma vez que a Proteção Integral afirmada no Estatuto da Criança e do Adolescente é diferente da proteção assistencialista-correcional presente nos Códigos de Menores de 1927 e 1979. Neste sentido, consideramos que a Proteção Integral pressupõe uma tensão, e não uma contradição, entre proteção e autonomia, entre sujeito de direitos e pessoa em desenvolvimento, entre prioridade absoluta e os demais interesses existentes na sociedade - reconhecendo, no entanto, a urgente necessidade de aprofundarmos este debate, em virtude das consequências para a formulação e execução das políticas públicas, que advêm das normativas nacional e internacional. Segundo Melo (2008), é necessário compreendermos 
o quanto a mudança de paradigmas não pode se dar sem um aprofundamento sobre as várias dimensões normativas que ditam o controle da sexualidade e seu caráter eminentemente político. Sem uma ênfase na reflexão sobre o lugar social de crianças e adolescentes e as discriminaçôes etárias e de geraçôes a que estão expostos, não se poderá reconhecer efetivamente suas competências e seu direito à participação e ao exercício de seus direitos. Pretender falar de novos direitos no campo da sexualidade e de uma justiça voltada à emancipação dos sujeitos não será possível, no campo dos direitos humanos, sem uma revisão de conceitos como proteção e desenvolvimento, de norma e direito, e, sobretudo, de protagonismo social de crianças e adolescentes (Melo, 2008: 16).

Ao nosso ver, é este debate de fundo que está faltando no Brasil, levando-nos a ambiguidades e inconsistências. Neste sentido, é necessário que um grande debate se instale entre as diversas categorias profissionais e os diversos componentes do Sistema de Garantia de Direitos e das Redes de Atendimento, não limitando a compreensão do art. 12 da Convenção às metodologias e técnicas de inquirição judicial, mas ampliando e aprofundando o debate na perspectiva da integralidade e da indivisibilidade dos Direitos Humanos, fortalecendo as políticas públicas inclusivas e de qualidade e valorizando o protagonismo infanto-juvenil.

\section{REFERÊNCIAS BIBLIOGRÁFICAS}

Azambuja, M. R. F. (2006). Violência sexual intrafamiliar: interfaces com a convivência familiar, a oitiva da criança e a prova da materialidade. Revista dos Tribunais, 852, 424446.

Arantes, E. M. M. (2008). Consideraçôes sobre o substitutivo ao projeto de lei n. 4126 de 2004. Texto apresentado em 1o de junho de 2008, em Audiência Pública no Senado Federal, Brasília, DF. Disponível em: <http://www.pol.org.br/pol/cms/pol/debates/ direitos_humanos/direitos_humanos_080829_0001.html>. . (2009). Pensando a Proteção Integral. Contribuiçôes ao debate sobre as propostas de inquirição judicial de crianças e adolescentes como vítimas ou testemunhas de crimes. (pp. 79-99) In: Falando sério sobre escuta de crianças e adolescentes envolvidos em situaçôes de violência e a rede de proteção. Brasília: Conselho Federal de Psicologia.

Castanha, N. (org.). Direitos sexuais são direitos humanos. Brasília: Comitê Nacional de Enfrentamento à Violência Sexual contra Crianças e Adolescentes.

CONANDA. (2008). Nota Pública. Recuperado em 04 de setembro de 2009. Disponível em <http://www.mndh.org.br/index.php?option...>. 
Convenção sobre os Direitos da Criança. Recuperado em 04 de setembro de 2009. Disponível em <http://www.onu-brasil.org.br/documentos_convencoes.php>.

Convenção sobre os Aspectos Civis do Sequestro Internacional de Crianças. Recuperado em 04 de setembro de 2009. Disponível em <www2.mre.gov.br/dai/seq.htm>.

Cristo, A. (2009). Disputa envolve leis brasileiras, americanas e acordos internacionais. Recuperado em 04 de setembro de 2009. Disponível em Conjur: <http:// www.conjur.com.br/2009-mar-10/guarda-sean-envolve-leis-brasileiras-americanas-acordo-internacional>.

Darlan, S. (2009). A criança chega ao Supremo Tribunal Federal. Recuperado em 04 de setembro de 2009. Disponível em A voz do cidadão. Instituto de cultura de cidadania: <www.avozdocidadao.com.br/detailArtigo.asp?...>.

FNDCA. (2009). Manifesto em defesa dos Direitos Humanos Infanto-juvenis. Recuperado em 04 de setembro de 2009. Disponível em <http://www.cfess.org.br/arquivos/ Manifesto_FNDCA.pdf>.

Globo.com (2009). Italiano é preso por beijar a filha na boca em barraca de praia no CE (G1, em 03/09/09 - 13h21 - Atualizado em 03/09/09 - 14h 14).

Matta, E. L. C. \& Correia, V. de M. (2008). Direito Penal e Direito Sexual e Reprodutivo de Crianças e Adolescentes. Contradições e Antagonismos. In: Castanha, N. (org.). Direitos sexuais são direitos humanos (pp. 69-80). Brasília: Comitê Nacional de Enfrentamento à Violência Sexual contra Crianças e Adolescentes.

Melo, E. R. (2008). Direito e norma no campo da sexualidade na infância e na adolescência. In: Criança e adolescente. Direitos e sexualidades (pp. 16-26). São Paulo: ABMP e Childhood Brasil.

Nicodemos, C. (2008). Do Direito Penal da vítima à vitimologia. A experiência do Programa de Proteção às Crianças e Adolescentes Ameaçados de Morte da ODH Projeto Legal. In: Nicodemos, C. (org.). PPCAAM (pp. 6-9). Rio de Janeiro: ODH Projeto Legal.

Nogueira Neto, W. (2008). Direito afetivo-sexuais da infância e da adolescência: o papel dos Conselhos dos Direitos da Criança e do Adolescente. In: Criança e adolescente. Direitos e sexualidades (pp. 56- 79). São Paulo: ABMP e Childhood Brasil.

O Globo. (2009). Menina é morta após ver pai ser assassinado. Rio de Janeiro: Edição de 09/02/2009, p. 12.

O Globo. (2009). Ministro defende que Sean fique no Brasil. Vannuchi diz, no entanto, que menino não deve ser forçado a decidir entre o pai americano e o padrasto. Rio de Janeiro: Edição de 23/04/09, p. 12.

O Globo. (2009). "Não houve malícia”, diz mulher de italiano preso. Rio de Janeiro: Edição de 06/09/2009, p. 12. 
Souza, S. J. (2008). Criança e adolescente: construção histórica e social das concepções de proteção, direitos e participação. In: Criança e adolescente. Direitos e sexualidades (pp. 7 15). São Paulo: ABMP e Childhood Brasil.

Théry, I. ([1992] 2007). Novos direitos da criança - a poção mágica? In: Altoé, S. (org.). A Lei e as leis. Direito e psicanálise (pp. 135-161). Rio de Janeiro: Livraria e Editora Revinter Ltda.

Uchôa, A. (2009). Tenho pavor da Justiça brasileira, diz pai de menina de 4 anos (G1, em 21/06/09 - 18h18 - Atualizado em 22/06/09 - 12h14).

Recebido em 08 de junho de 2009 Aceito para publicação em 25 de novembro de 2009 